\title{
A Collaborative IOT based Agriculture Marketing Model
}

\author{
Vedavathi Katneni, K. SuryaPrakash
}

\begin{abstract}
Agriculture Marketing in India is currently highly influenced with modern information technology. Latest GPS and GIS system based informatin extraction mechnisms providing high scaled details in realtime environments. In this paper a noval model constructed based on IOT enabled services to support modern Agriculture marketing feasible to farmer. The primary market dynamics are highlighted to show their impact on agriculture marketing system. The Collaborative model suggested in this work not only supports farmer in marketing their crops with best economy but also helps analysts to study the marketing trends and their various factors using knowledge engineering mechanisms. This model behaves in a highly farmer suggestive mode. The collaboration with international marketing is one of the major goals of proposed model.

Keywords: Internet of Things, Cloud Computing, Data Mining, Agriculture Marketing, Sensors.
\end{abstract}

\section{INTRODUCTION}

Agriculture is the largest industry on which India economic growth highly relied [4]. Major activities like farming, cultivation, crop management, pest management and marketing are the key functions of agriculture and allied industries [8]. The IOT technology application in agriculture marketing improves the connectivity of market entities with physical entities globally with smart Service-Oriented-Architectures [2]. Farmers are allowed to get awareness of international marketing trends by the cloud enabled services also economic improvement noticed with mobile computing facilities [3]. Big Data Analytics domain facilitated analysts, economists, organizations and government to perform large scale data engineering received from sensors, social media, GIS/GPRS systems and Cloud servers [5][9]. The integration of elctronic sensors, radio frequency Identifiers (RFID), Scanning Ssytems, Drones and Global Positioning Systems improved drastically the performance of Geographical/Social/environmental survey with greater data acqution rate maintaining high accuracy. The modern agriculture marketing integrated with IOT

Revised Manuscript Received on March 17, 2020.

* Correspondence Author

Dr Vedavathi Katneni*, Research Guide, Department of Computer Science, GITAM University, Vizag, INDIA. Email: bsamhirama@yahoo.com

Kola Surya Prakash, Research Scholar, Department of ComputerScience, GITAM University, Vizag, INDIA. Email: bsamhirama@yahoo.com

(c) The Authors. Published by Blue Eyes Intelligence Engineering and Sciences Publication (BEIESP). This is an open access article under the CC BY-NC-ND license (http://creativecommons.org/licenses/by-nc-nd/4.0/) entities improving the Supply Chain Operations more dynamically [10][5]. The IOT gateways are turning more robust to resist security breaches and supporting agriculture safe marketing by encrypting farmer's credentials or assets [10]. Precision Agriculture is becoming a new generation locality based smart IOT technology assisted agriculture managenet widely accepted in many foreign countires gaining high interest of research in India [12]. The marketing statistics are now analyzing by knowledge learners like Neural Networks, Genetic Algorithms, Fuzzy Lofic, Navie Bayes classifiers, PCA and many more to estimate future trends coining the prosperity of farmers [11].

\section{RELATED WORK}

Many researchers performed analysis and experiments to identify the improvements in IOT based agriculture and marketing techniques. They proposed many models to support agriculture domain productivity enhancement.

D.N. Chethan et. al., (2016) described a new approach to support farmers using farm cloud and Mobile-App module. Privacy preserving Data Mining based advanced farming architecture improves production and controls cost.

Dipali Kadam et. al., (2015) implemented an IOT supported Agro-Cloud model with sensor kit module integration. Big data analysis service provided with this model efficiently handles soil analysis, crop production analysis and fertilizer analysis.

K. Ravindranath et. al., (2019) proposed a three tier based smart agriculture model, which effectively performs automatic irrigation activities with real-time electronic device interfacing.

D.Rajesh et. al., (2011) performed cluster analysis, pattern analysis, classification and association mining techniques over agriculture spatial data to enhance the precision of agriculture.

Ashan Abdullah et. al., (2018) performed research on predicting cultivable regions over territories using GIS tools like ArcGIS, QGis and SPOT (Spatial Prediction and Overlay Tool).

S.Bhuvana et. al., (2016) proposed IOT infrastructure interlaced with spatial data mining techniques to identify the farming influencing factors to assist agriculture productivity.

Mythili. R et. al., (2018) experimented with Audrino processor to develop monitoring systems collaborative with IOT entities.

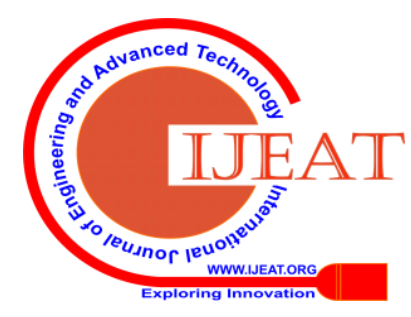


These systems increased the automation and accuracy of agriculture activities like crop monitoring, weather monitoring and product chain monitoring.

\section{MARKETING DYNAMICS}

It is necessary to understand about influenciing factors that affect the agriculture marketing. The business surveys identified following dynamics accordings to statistics [2016-2018].

Climate - Natural disasters, climatic changes, droughts and low rainfalls impacts the agriculture yield declined to $19 \%$ to $26 \%$. IOT services increases yield and cultivation effeciency considerably during inauspious weather conditions.

Water Conservation - The consumation of fresh water is high in agriculture nearly $70 \%$. The irrigation systems need more moderation with the help of IOT for efficient water utilization in agriculture.

Resources - The agriculture activities like sowing, cultivation, pest management and harvesting effectively improved with the IOT services. The crop yield rate is directly proportional to above factors.

Deployment - The crop deployment services influenced with various factors like storage, agencies, territory assets and transportation. IOT supported deployment services improve the Return of Investment (ROI) along with agriculture product quality.

\section{PROPOSED MODEL}

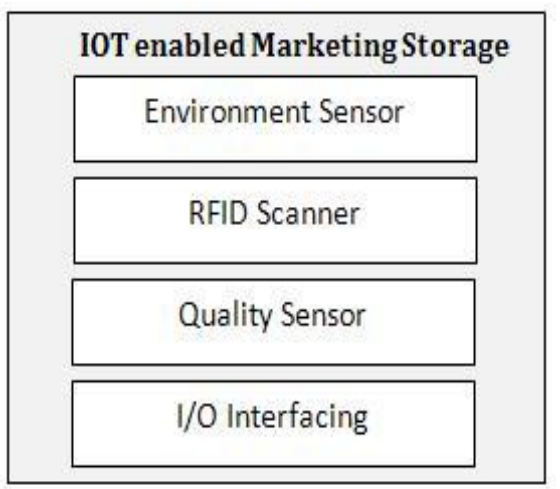

Fig. 1. IOT Storage Room

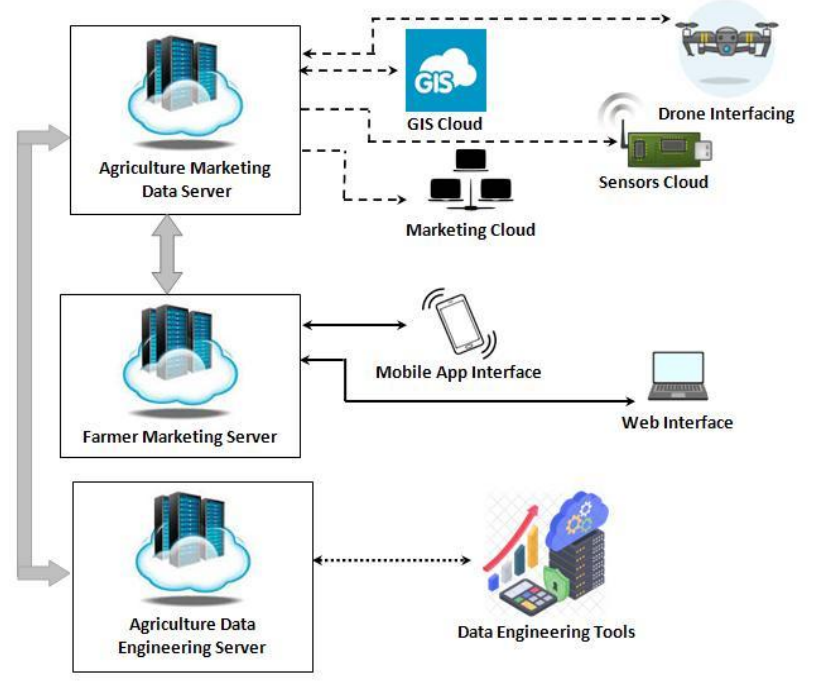

Fig. 2. Collaborative IOT Agriculture Marketing Model

\section{A. IOT Storage Room}

The modern marketing storage pits need to be IOT interfaced for scalability and performance oriented support to Agriculture Marketing. In Fig 1 an IOT enabled storage room proposed which supports high quality digital equipment interfacing for farmer market association.

'Environment Sensor' equipment integrated to monitor Humidity, Temperature, Ventilation dynamics and Light intensity metrics in real-time. 'RFID Scanner' maintains the product information with confidentiality. 'Quality Sensor' drone type equipment that supported with Ultrasonic/Laser/X-ray scanning which finds the internal product patterns to detect the quality. The sensor devices supported with good I/O interfacing facilities to communicate with mobile devices, display panels and cloud services. Authorities can get information about the products and their quality inside the agriculture granaries at any instant from mobile app without manual checking.

\section{B. Collaborative Agriculture Marketing Model \\ Agriculture Marketing Data Cloud Server}

The central data server responsible for colloborative framework supports functionalities as follows.

- 'Sensors cloud' providing all service modules to aquire data from electronic sensor devices (Farm Monitors, warehouse monitors, granary scanners etc.) tracking of multi-dimensional data in real-time using IOT interfaces is primary concern for this cloud server.

- 'GIS Cloud' server supports modules and services for data aquition from GIS/GPRS systems employed for agriculture marketing data collection globally.

- 'Drone Interfacing' server co-ordinates and gathers information from agriculture drones which scans details of marketing products located at farms or granaries.

- 'Marketing Cloud' server holds all the national and international agriculture marketing services with wide range of statistical data representation formats. Several marketing domains are integrated in this cloud to support farmer.

\section{Farmer Marketing Cloud Server}

The cloud server facilitates mobile app service oriented interaction with farmers. The web interface is also supported. Agriculture marketing services like crop management, cultivation management, crop quality assessment, farm testing services, marketing schemes, storage centres services, agriculture business services, International marketing and market analysis are the affordable services provided to farmers by this mobile app. The app supports assistance to farmer clients ranging from begineers to advanced (who can utilize data analytic services also).

\section{Agriculture Data Engineering Cloud Server}

The Data Engineering is a process of applying data mining tools application over training data sets to identify the required meaningful information patterns.

Published By:

Blue Eyes Intelligence Engineering

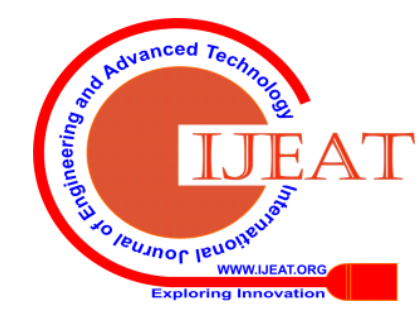


In colloboration with Agriculture Marketing Server supports agriculture marketing data analysis with wide range of data mining service modules. Performs knowledge engineering tasks like decision supportive summaries, Trend analysis, probability estimations, classification rules, associative patterns, aggregation, generalization, data cube operations and feature learners generation. Provides cloud based modern visualization techniques. The analysts depend on this information to effectively organize the mobile cloud app services through 'Farmer Marketing Cloud Server'.

\section{Collaboration of Cloud servers in IOTAMM}

Table- I: Collobation of Cloud Servers

\begin{tabular}{|c|c|c|}
\hline Cloud Server & Colloborative to & Data \\
\hline $\begin{array}{c}\text { Agriculture } \\
\text { Marketing Data } \\
\text { Server }\end{array}$ & $\begin{array}{c}\text { Farmer } \\
\text { Marketing Server }\end{array}$ & $\begin{array}{c}\text { Sensor data } \\
\text { Global Marketing data } \\
\text { Field Dron data }\end{array}$ \\
\hline $\begin{array}{c}\text { Farmer } \\
\text { Marketing Server }\end{array}$ & $\begin{array}{c}\text { Agriculture } \\
\text { Marketing Data } \\
\text { Server }\end{array}$ & $\begin{array}{c}\text { Mobile Client data } \\
\text { Web Client data }\end{array}$ \\
\hline $\begin{array}{c}\text { Agriculture Data } \\
\text { Engineering } \\
\text { Server }\end{array}$ & $\begin{array}{c}\text { Agriculture } \\
\text { Marketing Data } \\
\text { Server }\end{array}$ & $\begin{array}{c}\text { Big Data Analytics } \\
\text { KDD } \\
\text { OLAP Server data } \\
\text { Visualization data }\end{array}$ \\
\hline
\end{tabular}

The colloborative information exchange among the three servers made the proposed model more efficient in assisting farmer agriculture marketing activities mobile app. Each farmer has to register himself to marketing server as a secured client using their mobile app. The information exchange among mobile client to cloud server is highly encrypted using MD5/SHA-2 algorithms.

\section{CASE STUDY \& RESULT ANALYSIS}

In this case study an agriculture marketing domain (Siriculture) activities are studied under the IOT model environment. The proposed model benefits are highlighted over existed IOT and traditional marketing technologies.

\section{A. SiriCulture Farming at Chebrolu}

The Siriculture farm at chebrolu East Godavari district is famous for its productivity since 30 years. There are 3-Labs and 4 farms spawned across 25 Acres of land. The data collected from agriculture office authorizing the Siriculture farm. A comparitive analysis performed over ststaistics collection during year 2015-2016(before IOT adoption) and statistics collection during year 2017-2018(after IOT adoption). The lab environmental metrics used as training data sets for following analysis.

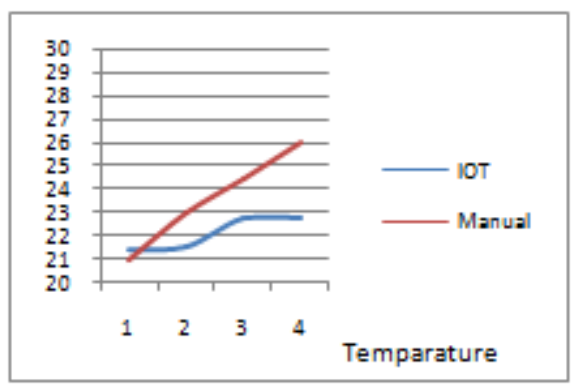

Sampling Efficiency

$$
\text { Sampling Efficiency }(S E)=\frac{\text { No. of Samples }\left(N_{s}\right)}{\text { Unit Time }(T)}
$$

The experimental observations identified that IOT based metrics collection is 60 average samples per 5 minutes whereas manual sampling collection rate is 5 samples per 5 minutes. Hence SE (IOT) is 12 times more than the SE (manual). The IOT sampling accuracy is highly similar to human expert sampling accuracy as shown in Fig (3-6). When compared with metrics recorded with human experts IOT maintained a high accuracy. During a timeslice (5 Minutes) statistical comparison resulted a variance of VAR $=0.05432$ and standard deviation STDEV=0.2324 which is a negligible difference.

\section{B. ROI Evaluation}

The Return of Investment (ROI) is a business factor to estimate the marketing efficiency of a domain with current dynamics. In this case study Siriculture farm marketing statistics among traditional and IOT enabled are analyzed. The Table II represents the fiscal report abstraction to calculate ROI.

Table- II: IOT Vs Traditional Marketing ROI

\begin{tabular}{|c|c|c|c|}
\hline $\begin{array}{c}\text { Approach/ } \\
\text { Model }\end{array}$ & Gain & Invest_Cost & Labour_Cost \\
\hline IOT & Rs. 140000 & Rs. $1,35,000$ & Rs. $1,15,000$ \\
\hline Traditional & Rs. 85,000 & Rs. 2,75,000 & Rs. 2,45,000 \\
\hline
\end{tabular}

$$
R O I=\frac{\left[\text { Net }_{\text {Income }}-\left(\text { Current }_{\text {Value }}-\text { Original }_{\text {Value }}\right)\right]}{\text { Original }_{\text {Value }} X 100}
$$


Return of Investment (IOT Approach) resulted as 103.7\% yielding factor and for Traditional approach resulted as $30.9 \%$ yielding factor. This clearly shows that proposed IOT model significantly improved marketing profit for farmers compared to traditional marketing model as shown in Figure 7.

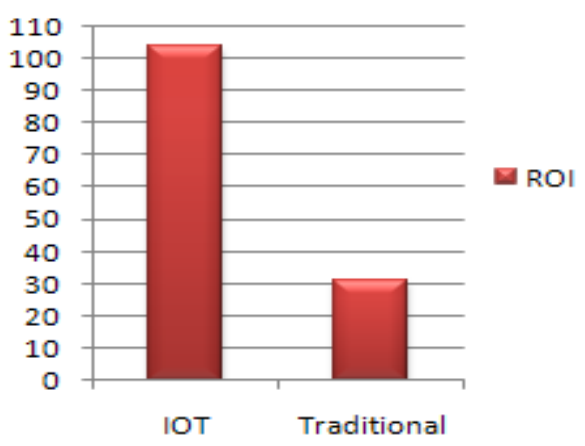

Fig. 7. IOT Vs Traditional ROI

\section{Proposed Model Features}

The colloborative model proposed in this work supports following services to the Siriculture farm to enhance the existed IOT without Knowledge engineering technology.

- Mobile app based farmer connectivity to data cloud centres to improve QoS.

- ISO standardization for agri-product from for international marketing.

- Secured International Marketing Gate-ways.

- Global standards advisory service.

- Smart devices interfacing guidelines with modernizing suggestive summaries.

- Global mechanisms for quality assurance

- International/National market trends real-time monitoring with data analysts supporting advices.

- Brokeraging, Marchendies, Distribution and Banking services with farmer profitable views

Figure 8 shows triangular colloborative assistance to agriculture marketing empowerment for farmer prosperity.

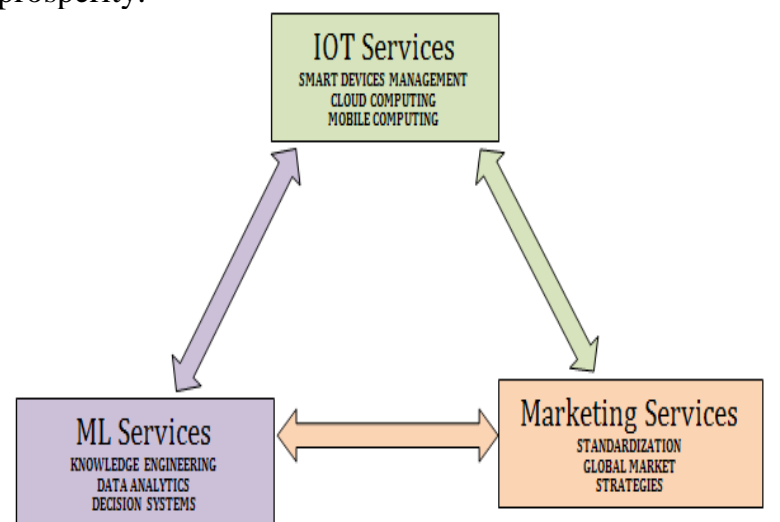

Fig. 8. Colloborative modules in model

The triangular ineraction among three cloud server modules show a stronger information exchange bridge between them. Each module is securely transparent to other module with efficient knowledge integration.

\section{CONCLUSION \& FUTURE WORK}

The work in this paper projects a modernized layot of IOT based agriculture marketing environment which improves the productivity and economy of farmers. The results showed a considerable efficiency variance among traditional agriculture marketing and IOT agriculture marketing. The colloborative model improves the 'Quality of Service' to farmer using diverged cloud servers performing multi-variety knowledge discovery and decision support. This model is recommended for community farming where the capital investiment can be shared among community. In future work the colloborative model prototype implementation using J2ME and .net softwares to study the real time application behaviour with assistance of mobile app module to be aimed.

\section{ACKNOWLEDGMENT}

Author is thankful to Agriculture department of Chebrolu for permitting this work by providing data and support. Special thanks to Technical Engineer, Lab and Farm supervisors for their consistent support in data collection.

\section{REFERENCES}

1. Veerpal Kaur, "Role of IOT in Agriculture", $2^{\text {nd }}$ International Conference on Food Security, Nutrition and Sustainable Agriculture Emerging Technologies, Journal of Pharmacognosy and Phytochemistry, pp. 422-425, Febraury-2019, India.

2. K. Ravindranath,"Cloud of Things for Smart Agriculture", IJTTEE Vol.8, ISSN: 2278-3075, pp. 30-33, April-2019.

3. K.T. Chandra Shekhara, P. SesiMohan., "Advanced Farming Using Smart Technology”. IJCSE, CSTAR Conference, Bangalore, e-ISSN: 2347-2693, 2016.

4. J. Agarkhed, "IOT based WSN for Irrigation System-A Review”, IJRAT, Vol.5, e-ISSN: 2321-9637, pp. 26-29, October-2017.

5. Hemlata Channe, "Multidisciplinary Model for Smart Agriculture using IOT, Sensors, Cloud Computing \& Big-Data Analysis”, IJCTA, Vol.6, pp. 374-382, June-2015.

6. J. Wang, "Fundamentals of erbium-doped fiber amplifiers arrays (Periodical style-Submitted for publication)," IEEE J. Quantum Electron., submitted for publication.

7. C. J. Kaufman, “An Analysis of Crop Field Data Mining Techniques in North Eastern States”, Rocky Mountain Research Lab., Boulder, CO, private communication, May 1995.

8. Mythili. R, D. Pradeep Raj, "Survey of Data Mining Techniques and Applications of New Techniques in Agriculture", IOSR-Journal, ISSN: 2278-8719, pp. 31-35, ICCIDS-Conference, Coimbatore- INDIA, 2018

9. N. Mirjankar, "Application of Data Mining in Agriculture Field", IJCEA, pp. 363-368, ICCSTAR-Special Issue, May-2016.

10. D. Rajesh, "Application of Spatial Data Mining for Agriculture”, IJCA, Vol.15, No.2, February-2011.

11. Dr G. Narasimha, Aakunuri Manjula, "Crop Yield Prediction with Aid of Optimal Neural Network in Spatial Data Mining: New Approaches", IJICST, ISSN: 0974-2239, Vol. 6, November-2016.

12. G. Rub and Alexander, "Data Mining in Precision Agriculture Management of Spatial Information", pp.350-359, IPMU Conference, Springer, Berlin, 2010.

\section{AUTHORS PROFILE}

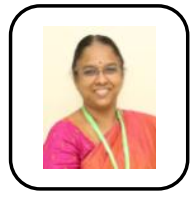

Dr Katneni Vedavathi is currently working as HOD of Computer Science department, GITAM, Visakhapatnam. She completed her Ph.D. from Andhra University. She is member of CSI, Indian Science Congress and ISTE. She received multiple awards. Her areas of interest are Data Mining, Cognitive Learning, Machine Learning and IOT.

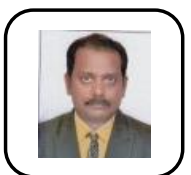

Kola SuryaPrakash pursuing Ph.D. in Computer Science at GITAM, Visakhapatnam. He worked as Assistant Professor in SRK Government College of Comuter Science department. He Completed his MCA from Madras University affiliated college and M.Phil from Madurai Kamaraj University. His areas of interest are Data Mining, IOT and Machine Learning.

Published By:

Blue Eyes Intelligence Engineering

\& Sciences Publication (C) Copyriaht: All riahts reserved. 